\title{
O colapso da formação: da Universitas sapiens para a Universitas economica
}

\section{The collapse of formation: from Universitas sapiens to Universitas economica}

\section{El colapso de la formación: de Universitas sapiens a la Universitas econômica}

\author{
Fabio Caires Correia ${ }^{1}$ \\ Gillianno José Mazzetto de Castro ${ }^{1}$
}

DOI: http://dx.doi.org/10.20435/serie-estudos.v26i58.1541

\begin{abstract}
Resumo: O uso do termo colapso no título pode parecer estranho. Como colapso se as instituições, e, no caso aqui em questão, a universidade, continuam a operar normalmente? De acordo com a lógica do senso comum, e com certa razão, a universidade não deixou de fazer aquilo que ela é "obrigada" a fazer, leia-se, restituir à sociedade pessoas profissionalmente preparadas. Ela continua a fazê-lo, ainda que (1) sob novas regras, (2) sob novas condições e ainda que (3) sob outro signo. Colapso não significa o congelamento de seu funcionamento, i.e., a interrupção abrupta de suas funções, ou mesmo o impedimento de cumprir com sua finalidade. É, antes de mais nada, deixar de se pautar por sua própria história, esquecendo-se de atentar para aquilo que, desde suas origens, Ihe é mais caro. Nosso objetivo neste presente texto é pensar a universidade, por conseguinte, a formação per se. Isso exige localizarmos no tempo um modelo de universidade que, a nosso ver, caracteriza bem a crise de identidade que nossa formação vive no momento. Last but not least, queremos mostrar que a crise da modernidade é, em larga escala, crise do pensamento, mais ainda, crise de um modelo institucional de pensamento.
\end{abstract}

Palavras-chave: universidade; formação; instrumentalização; economia.

Abstract: The use of the term collapse in the title may seem strange. How does it collapse if the institutions, and in this case, the university, continue to operate normally? According to the logic of common sense, and with some reason, the university did not fail to do what it is "obliged" to do, that is, to restore professionally prepared people to society. It continues to do so, even if (1) under new rules, (2) under new conditions, and even (3) under another sign. Collapse does not mean the freezing of its functioning, i.e., the abrupt interruption of its functions, or even the impediment of fulfilling its purpose. It is, first of all, to stop being guided by its own history, forgetting to pay attention to what, since its origins, is most dear to it. Our objective in this present paper is to think about the university, therefore, the formation per se. This requires us to locate in time a university

\footnotetext{
${ }^{1}$ Centro Universitário Católica do Tocantins (UNICATÓLICA), Palmas, Tocantins, Brasil.
} 
model that, in our view, characterizes well the identity crisis that our formation is experiencing at the moment. Last but not least, we want to show that the crisis of modernity is, on a large scale, a crisis of thought, more so, a crisis of an institutional model of thought.

Keywords: university; formation; instrumentalization; economy.

Resumen: El uso del término colapso en el título puede parecer extraño. ¿Cómo colapso si las instituciones, y, en este caso, la universidad, siguen funcionando con normalidad? Según la lógica del sentido común, y con alguna razón, la universidad no dejó de hacer lo que está "obligada" a hacer, es decir, restituir a la sociedad a personas preparadas profesionalmente. Continúa haciéndolo, incluso si (1) bajo nuevas reglas, (2) bajo nuevas condiciones e incluso (3) bajo otro signo. Colapso no significa el congelamiento de su funcionamiento, es decir, la interrupción brusca de sus funciones, o incluso el impedimento para cumplir con su propósito. Es, ante todo, dejar de guiarse por su propia historia, olvidándose de prestar atención a lo que, desde sus orígenes, le es más querido. Nuestro objetivo en el presente texto es pensar en la universidad, por tanto, la formación en sí. Esto nos obliga a ubicar en el tiempo un modelo universitario que, a nuestro juicio, caracteriza bien la crisis de identidad que vive nuestra formación en estos momentos. Por último, pero no menos importante, queremos mostrar que la crisis de la modernidad es, a gran escala, una crisis del pensamiento, más aún, una crisis de un modelo institucional de pensamiento.

Palabras clave: universidad; formación; instrumentalización; economía.

A universidade está reservada para o que a pessoa só pode encontrar por ela própria e nela própria: o acesso (Einsicht) à ciência pura. Para esse ato próprio (Selbst Actus) em direção ao entendimento mais próprio, é necessário liberdade e uma solidão (Einsamkeit) útil - e é a partir desses dois pontos que, ao mesmo tempo, flui toda a organização externa das universidades. Seguir cursos é apenas algo lateral. O essencial é estar em comunidade próxima com pessoas da mesma opinião e com os pares, e a consciência de que, no mesmo lugar, já existe um número de pessoas que já completaram sua formação (vollendet Gebildeter) que se dedicam apenas à elevação e à difusão da ciência. (Wilhelm von Humboldt, 2010).

\section{INTRODUÇÃO}

À primeira vista, o uso do termo colapso no título pode parecer estranho. Como colapso se as instituições, e, no caso aqui em questão, a universidade, continuam a operar normalmente? De acordo com a lógica do senso comum, e com certa razão, a universidade não deixou de fazer aquilo que ela é "obrigada" a fazer, leia-se, restituir à sociedade pessoas profissionalmente preparadas. Ela continua a fazê-lo, ainda que (1) sob novas regras, (2) sob novas condições e ainda que (3) sob outro signo. Colapso não significa o congelamento de seu funciona- 
mento, i.e., a interrupção abrupta de suas funções, ou mesmo o impedimento de cumprir com sua finalidade. É, antes de mais nada, deixar de se pautar por sua própria história, esquecendo-se de atentar para aquilo que, desde suas origens, Ihe é mais caro, a saber: "[...] formar pessoas com alto sentido cultural, moral e político de cidadania e de contribuir, em sua esfera de possibilidades e em seus limites, para a solução de problemas da coletividade" (DIAS SOBRINHO, 2015, p. 584). A responsabilidade das universidades não reside apenas na técnica, mas também na ética e na política. Grosso modo, este é o modelo humboldtiano de universidade. Na verdade, o conhecimento que produz só será socialmente relevante, se e tão somente se estiverem nele incluídos a economia e as demais esferas do campo social. Há na instituição universitária o compromisso inerente com o desenvolvimento regional, e isto amplia o seu escopo e a sua atuação para além dos cenários econômicos e mercadológicos.

Contudo, no cenário brasileiro, nota-se cada vez mais forte a tentativa de submeter as instituições universitárias à lógica da prestação de serviço ou ainda de uma formação acelerada, sustentada por um viés eminentemente técnico, que acaba se isentando, em muitos casos, a fortiori, das suas prerrogativas de espaço indutor de formação integral e integralizante 2 . Este é o ponto de colapso e ponto de implosão de um modelo e de um simbolismo. Para citar um caso bastante específico, mas que em muito se assemelha ao nosso, Michel Freitag (1995), em Le naufrage de l'université et autres essays d'épistémologie politique, mostra, de maneira bastante pertinente, que o poder exercido pelas forças hegemônicas condiciona a universidade à abordagem de questões puramente pragmáticas. $\mathrm{O}$ objetivo dessas forças é evidente: pôr a universidade a serviço da ordo vigente, qual seja, da economia de mercado, tornando a sala de aula e o ensino uma fábrica de sujeitos eficientes, prontos para serem inseridos - ainda que no nível da promessa - no mercado de trabalho. O autor denomina universidade operacional aquela que se torna uma organização a serviço do mercado, preocupada com a formação massiva da mão de obra, e a contrapõe à universidade tradicional, interessada na acumulação de conhecimentos, na formação integral e na difusão da cultura. Ainda que inúmeras transformações tenham ocorrido de lá para cá, Freitag acerta quando percebe uma inversão no próprio sentido de existência

\footnotetext{
2 Essa posição é amplamente defendida, por exemplo, por Dias Sobrinho (2002; 2004; 2005; 2013), Goergen (2010; 2011; 2013), Oliveira (2009), Sguissardi (2015), entre outros.
} 
da universidade. Quando ela deixa de ser uma instituição e passa a ser uma organização, com fins muito bem delimitados. "Regida por contratos de gestão, avaliada por índices de produtividade, calculada para ser flexível [...] estruturada por estratégias e programas de eficácia organizacional e, portanto, pela particularidade e instabilidade dos meios e dos objetivos" (CHAUÍ, 2003, p. 7). Essa lógica organizacional, cuja agenda acadêmica internacional prevaleceu desde o final da década de 1990, gira em torno de dois grandes eixos relativos à universidade. Em primeiro lugar, ficou claro como a pressão de mudança foi gerada pelas demandas, especialmente no Brasil, da então insurgente economia neoliberal, que, devido à intensa competição mundial, incluíram modelos de produção flexíveis e com o uso de tecnologia de ponta para aumentar a competitividade internacional. Tal realidade se traduziu na segmentação do mercado e nas demandas de reorientação das políticas educacionais para atender a um mercado de trabalho fragmentado, que demandava a téchne da gestão e da fiscalização (vide processos de acreditação) com habilidades para atender a esses processos. Ao mesmo tempo, e com a expansão do mercado de serviços, exigia-se das universidades um pessoal qualificado, sob os critérios da utilidade e da operation, para seu atendimento.

Uma segunda fonte de pressão por mudanças foi a forçada e estratégica retirada do Estado para manter o financiamento da educação pública e a consequente abertura do setor educacional ao setor privado3. "O privado ocupou o lugar do público, seja em investimentos seja em imposição e implementação de demandas" (CORREIA, 2016, p. 34). Isso gerou uma ressemantização conceitual da educação superior, visto que ela já é percebida como um mercado, i.e., (a) gerida

\footnotetext{
${ }^{3}$ De acordo com Sguissardi, "[...] sob pressão de organismos multilaterais, como o Banco Mundial e o Banco Interamericano do Desenvolvimento (BID), o então Ministro da Educação, Paulo Renato de Souza, ex-vice-diretor do BID em Washington, conduz o quase desmonte do 'setor' federal da educação superior, congelando os recursos financeiros e salários, e não criando nenhuma Ifes ao longo de dois mandatos presidenciais (1995-2002). Nesse mesmo tempo patrocinava o arcabouço jurídico - Decretos 2.207 e 2.306 de 1997 - para a legalização do 'negócio' da educação superior. Nisto seguia à risca as recomendações do Banco Mundial que, mediante três documentos - Financing education in developing countries - An exploration of policy options (WORLD BANK, 1986), de 1986; Higher education: the lessons of experience (WORLD BANK, 1994), de 1994; e The financing and management of higher education - A status report on worldwide reforms, (WORLD BANK, 1998) - disseminava algumas 'teses' que respaldariam as ações de governos dispostos a dar consequência ao ajuste neoliberal no campo educacional" (SGUISSARDI, 2015, p. 873).
} 
por prestações de serviços educacionais, (b) baseada na satisfação do cliente e (c) cuja finalidade é o lucro. Essa situação complexa produziu a ruptura do paradigma da análise da universidade; nas novas condições emergentes, tornou-se um novo desafio científico pensá-la.

Essas ideias propedêuticas marcam os pontos que doravante serão apresentados. São, a princípio, posições, orientações e desafios. Nosso objetivo é pensar a universidade, por conseguinte, a formação per se. Isso resulta na exigência de i) um método de análise e ii) de uma localização, no tempo e espaço, de um modelo de universidade que, a nosso ver, caracteriza bem a crise de identidade que nossa formação vive no momento (objeto). O método: a análise de modelos. O objeto: o modelo ocidental das instituições modernas. Last but not least, queremos mostrar que a crise da modernidade é, em larga escala, crise do pensamento, mais ainda, crise de um modelo institucional de pensamento.

\section{DOIS MODELOS, UM CENÁRIO: HUMBOLDT E PARIS}

Ao se pensar as instituições universitárias, principalmente aquelas que chegaram até os nossos dias, pode-se notar que os modelos e os regimes de verdade das sociedades que as estruturaram e alicerçaram também estão presentes no seu modus operandi. A universidade contemporânea nasceu entre os séculos XI e XII, primeiro na forma de Universitas Scholarium (associação de estudantes) e depois como Universitas Magistroum (associação de professores). Este ponto parece importante para nós, já que, no primeiro caso, grupos organizados de estudantes contratavam professores para Ihes dar formação básica e profissionalizante em medicina, direito ou teologia. Os alunos governavam a Universitas, e o reitor era aluno. O protótipo foi a Università di Bologna (1088). No segundo caso, os professores ofereciam os mesmos serviços aos jovens, mas eram os professores que governavam, e o reitor era professor; neste caso, o protótipo era a Université de Paris (1170).

É interessante ressaltar que as universidades vêm passando por crises desde muito tempo. A partir do século XIII, as universidades e, principalmente, suas faculdades de teologia tornaram-se guardiãs escolásticas, movimento político-cultural que teve como canalizar e controlar a difusão da tradição greco-romana (redescoberta pelos europeus em fontes árabes e do Oriente Médio) de forma que não questionasse a ordem social estabelecida. Nessa época, a 
universidade se instrumentalizava politicamente e perdia o caráter crítico que a distinguia em seus primeiros anos. O declínio das universidades levou muitas delas à irrelevância ou ao desaparecimento, eliminando a participação estudantil em seu governo. Nessa perspectiva, a partir do século XV, eles adotaram um papel obscurantista, opondo-se à Reforma e à ciência moderna. Finalmente, o paradigma da universidade medieval demonstrou seu esgotamento. A Revolução Inglesa, em 1642-1648, ameaçou a existência das Universidades de Oxford e Cambridge, e a Revolução Francesa eliminou a Universidade de Paris.

Somente durante os séculos XVII e XIX ocorreu o renascimento universitário, com os seguintes modelos: a Universidade Napoleônica (a Universidade de Paris refundada em 1806); a universidade inspirada por Wilhelm Von Humboldt (a Universidade de Berlim, em 1809) e a Escola Norte-Americana (antes do século 18). O modelo napoleônico é marcado pela força do conhecimento em favor da manutenção e promoção de um estado-nação. A universidade deixa de ser observada como o reduto dos intelectuais que questionam o soberano e, aos poucos, vai se tornando o lugar no qual a elite da nação é formada para servir aos interesses da própria nação. Ela passa a ser concebida como uma corporação ao serviço do Estado. Desse modo, há na universidade napoleônica, forte e marcadamente, um vínculo com a sociedade e um escopo para a vida da instituição universitária. Servir aos interesses do estado e fazer com que ele seja cada vez mais forte. É neste contexto que as especialidades se desenvolvem e o clássico trivium e quadrivium da universidade medieval vai desaparecendo. Pois, diferentemente do modelo de outrora, o papel da universidade não era mais o de formar para uma erudição e uma mathesis universalis, mas sim formar para uma técnica, que é a de prover ao estado-nação a mão de obra que ele necessita. Muito embora esta "mão de obra" não seja ainda envolta na perspectiva técnico-pragmática que observamos hoje.

No que se refere à origem do ensino superior na Alemanha, pode-se dizer que as demais universidades deste país foram fundadas no início do século XIX, sendo consideradas, junto das francesas, como iniciadoras do movimento universitário contemporâneo. É comum identificar Humboldt como o pai da universidade alemã contemporânea, pois não há dúvida de que ele, na companhia de outros intelectuais, contribuiu para imprimir as características que a tornaram um modelo. Atualmente, as contribuições das universidades alemãs para o desenvolvimento da educação superior no mundo, mais ainda, na América Latina, são indiscutíveis. 
Durante a época medieval, a educação alemã estava em desvantagem em comparação com o estado da educação na Europa. A desvantagem era particularmente no ensino superior. Devido a isso, jovens alemães foram enviados para estudar nas principais universidades da época, enquanto a Alemanha importava professores das universidades de Paris, Bolonha e Pádua. Essa dependência foi constante até o início do século XIX, quando essa situação foi mudando aos poucos, até o momento em que o país encontrou as condições necessárias para implantar um sistema de ensino superior com características próprias.

Uma das razões pelas quais esta região não tinha universidades de qualidade está relacionada aos conflitos políticos e religiosos que surgiram no período que vai do século XIV ao XVII. Tais conflitos eram de natureza nacionalista, e os problemas religiosos relacionavam-se, sobretudo, com a luta entre os católicos e o movimento protestante, que até se manifesta com características específicas nas universidades desta época. Sem sombra de dúvidas, a universidade contemporânea tem seu início na Alemanha no final do século XVII e início do século XVIII, e se consolida durante o século XIX. Na Universidade de Halle (1693), a liberdade de ensino e o seminário foram incorporados pela primeira vez como uma modalidade educacional. Em seguida, vem Göttingen (1737), que, além de retomar suas contribuições, incorpora a ciência como fio condutor. Porém, foi a Universidade de Berlim (1810) onde o processo de modernização se consolidou, pois, além da liberdade de ensino, do seminário e das ciências, incorpora-se ali a conferência como modalidade de ensino, o nível de pós-graduação como nível de formação por excelência e a figura do professor como protagonista. Assim, com essas inovações, surgiu a universidade alemã contemporânea no início do século XIX, promovida por intelectuais como Kant, Hegel, Humboldt, Fichte, Schelling, Schleiermacher, entre outros.

Neste contexto, o primeiro compromisso da universidade era o de produzir um conhecimento de caráter universal e universalizante, muito embora, como é sabido, tal conhecimento se restringisse a uma pequena e abastada parcela da população. A universidade em seu modelo europeu não era inclusiva, mas sim aristocrática. O modelo Humboldtiano introduz e influencia de maneira considerável o ideário em torno da universidade na contemporaneidade, a saber: uma instituição que produz ciência, que ensina este conhecimento aos seus membros e se vincula com a sociedade dentro da qual ela exerce a sua influência. Dentro deste 
modelo de instituição universitária, destaca-se: (1) a necessidade de cooperação entre professores e entre estes e o corpo discente; (2) a unidade entre o tripé ensino, pesquisa e extensão; (3) a complementaridade da educação básica com a superior; (4) a liberdade de produção da ciência pura; e, por fim, (5) a estreita relação, não obstante autônoma, entre Estado e universidade - uma universidade voltada para o desenvolvimento do Estado-Nação. Assim comenta Humboldt:

No que diz respeito à relação externa destas [instituições científicas superiores] com o Estado, basta que ele se limite a garantir a riqueza da força espiritual, isto é, seu poder e diversidade. O Estado promove tal riqueza na medida em que seleciona os cientistas e, ao mesmo tempo, assegura liberdade para seu trabalho. A autonomia fica ameaçada não apenas pelo Estado, mas também pelas próprias instituições quando, ao assumirem determinada orientação, impedem a emergência de qualquer outra. (HUMBOLDT, 2003, p. 87).

Dentro deste modelo, o processo de ensino-pesquisa se consolida e faz da universidade um espaço de livre pensamento. É dentro deste contexto que surgem as universidades livres, i.e., espaços universitários marcados pelo desenvolvimento e produção de pesquisas, por conseguinte, de pensamentos. As palavras de ordem eram Lehfreiheit, liberdade de ensinar; Lernfreiheit, liberdade de aprender (TEIXEIRA, 1964, p. 32; 1968, p. 41). Desse modelo, deriva aquilo que hoje se conhece por modelo norte-americano, o anglo-saxão, que, além de se estruturar como um espaço de pesquisa e desenvolvimento, tem uma preocupação em atender aos interesses da sociedade circundante. Tais instituições, por conta desse viés desenvolvimentista, acabam enfatizando e se voltando às ciências aplicadas.

Por outro lado, há também o modelo napoleônico que tem esta alcunha devido ao modelo inspirador do regime napoleônico na França. Este modelo orbita em torno de um rígido controle do estado sobre os professores, currículos e forma de ensinar e arregimentar as dinâmicas e rotinas universitárias, de tal forma que a universidade é também um símbolo do Estado-Nação. Disto se pode recordar o alerta feito por Florestan Fernandes, quando este afirma que é papel da universidade contribuir para o progresso da humanização e o desenvolvimento da sociedade (FERNANDES, 1975, p. 114-23; 2004, p. 273-316). Contudo, é preciso assumir uma postura crítica em relação a este ideário, verificando criticamente para onde e de quais formas este processo está apontando. 


\section{DA UNIVERSITAS ECONOMICA: SOBRE A UNIVERSIDADE OPERACIONAL}

Com o avanço das revoluções industriais e com fenômeno da aceleração, seja da cadeia produtiva, seja da impressão sobre a vida, como aponta Hartmut Rosa (2019), um novo modelo de universidade começa a surgir: a universidade econômica. A universidade econômica é fortemente marcada pelo fenômeno do "empresariamento da educação" (MARTINS, 2007; NEVES, 2002; 2005; RODRIGUES, 1998; 2007) ou mesmo por uma "pedagogização da empresa" (CORREIA, 2011, p. 172). Disto decorre que, dentro do ambiente universitário, palavras como mercado, cliente, performance, eficiência, começam a ganhar cada vez mais força, e a liberdade de ensinar e aprender - própria do modelo humboldtiano -, e do Estado-Nação - próprio do modelo napoleônico -, gradativamente vão dando lugar a lógica do MVP (Minimum, Viable Product) e dos modelos educativos em rede ou de grupos educacionais que, em muitos casos, têm por objetivo atender aos interesses econômico-financeiros dos seus acionistas.

O modelo da universidade econômica, que, após a revolução liberal de 1968, vem se instalando fortemente, apresenta alguns desafios para o processo de constituição da Universitas e parece apontar para novas perspectivas, a saber: a de customização do saber para reforçar o distanciamento de classes, pois as universidades classe mundial são aquelas que ainda conservam o espírito da Universitas e do livre pensamento. Por sua vez, as instituições regionais ou locais ficam ou marginalizadas e isoladas ou sucumbem ao movimento voraz de uma educação fast-food, transformando-se em empresas certificadoras. Contudo é mister explorarmos um pouco mais qual é a racionalidade inerente ao modelo de uma Universidade Econômica. Esta racionalidade advém do próprio critério norteador que, velada ou explicitamente, a rege, isto é, a racionalidade do Homo economicus, marcado, de acordo com Costa (2009) pelos seguintes paradigmas:

1. Uso exclusivo de uma racionalidade instrumental;

2. Mínimo esforço;

3. Atemporalidade;

4. Informação;

5. Universalidade.

Abordemos, ainda que panoramicamente, cada um destes pontos. O primeiro, o que se refere ao uso exclusivo de uma racionalidade instrumental (ADORNO; HORKHEIMER, 1985), tem como modelos a aplicabilidade, a operation e o uso 
imediato do conhecimento. Estes são supervalorizados em relação à pesquisa pura ou as ciências ditas básicas. É partindo deste modelo que curso de caráter técnico e/ou profissionalizante vem ganhando cada vez mais espaço dentro das instituições. A preparação para o mercado de trabalho é, sem dúvidas, a propaganda que fundamenta este modelo. Tal racionalidade instrumental, valendo-se da reflexão de Habermas (1989; 1990; 2000), pauta-se sobre um agir estratégico que se sustenta sobre a lógica dos meios e dos fins, fazendo com que toda forma de ação e de conhecimento seja submetida a uma lógica funcionalista de caráter responsivo e imediato.

O segundo ponto é a lógica do mínimo esforço que nas instituições universitárias econômicas tem sido traduzida sob a égide da prática de currículos mínimos e, mais ainda, acelerados. Um exemplo mais recente desta lógica é a criação dos nano e micro degrees (CLARKE, 2018). No que se refere à atemporalidade, esta pode ser observada pela lógica do imediatismo, de tal forma que o conhecimento dito clássico ou de outras épocas, devido a constante e cada vez mais enfática tecnologização da vida, fica relegado e tomado como obsoleto. Torna-se líquido para usar a expressão de Bauman (2001). Há na contemporaneidade a falsa, porém presente, impressão de que tudo aquilo que a humanidade produziu antes dos nossos dias pouco ou nada tem a contribuir com a nossa vida.

Um outro ponto muito presente como traço dos nossos tempos é a questão da informação. Contudo, junto deste acesso, a amplitude, o poder e a dinamicidade da informação se abrem à pergunta pela qualidade de seus processamentos, i.e., de como que as instituições de educação e, no presente caso, as instituições de educação superior têm contribuído para que, no processo formativo dos estudantes, se desenvolva uma competência para com a informação, ou mesmo para se lidar com ela (SILVA; NUNES; TEIXEIRA, 2020). Um elemento importante quando falamos do papel da informação na sociedade contemporânea é o da sensação que direta ou indiretamente ela produz no imaginário coletivo, qual seja, a ideia de uma emancipação igualitária que, em muitos termos, se revela frágil e ingênua (CARDOSO; FERREIRA; BARBOSA, 2020). Em qual chão assenta esta ingenuidade? A resposta nos parece de todo simples: se apoia na ideia de que o acesso à informação produziria um estado de emancipação do indivíduo e, por sua vez, de igualdade de condições dentro do todo social (MONTEIRO, 2020). O que a sociedade da informação tem ensinado, sob o ponto de vista da formação 
(Bildung), é que um modelo totalmente focado na informação e nos conteúdos pode contribuir pouco, ou quase nada, para o desenvolvimento da visão crítica e emancipatória dos estudantes.

Em muitos pontos, os provedores e buscadores de conteúdo da internet já em muito superaram os conhecimentos e os repositórios das instituições universitárias e, portanto, insistir em modelos curriculares focados em conteúdos e em modelos baseados na lógica de silos de conhecimento, tais como nos modelos clássicos das instituições universitárias, parece ser ineficaz diante deste contexto no qual a contemporaneidade se insere. Posto isto, é mister desenvolver uma atitude diferente diante do paradigma da informação, que, muito mais do que conteudístico, deve caminhar para um agir comunicativo, cujo escopo é o desenvolvimento das pessoas inseridas dentro da comunidade educativa.

Por fim, mas não menos importante, dentro do modelo da universidade econômica, é a universalidade, sob dois pontos de vista. O primeiro, que se refere à ampliação do acesso das camadas mais populares da sociedade à educação superior; e o segundo, do nascimento dos grandes centros globais do saber ou das instituições classe mundial (BARRIENTOS; ZAROR; HERNÁNDEZ, 2020). Quanto ao primeiro ponto, sob a ótica de universalização do acesso ao saber, a universidade econômica tem implantado um tipo de formação baseada na lógica do Mínimo Produto Viável de execução. A pergunta de fundo se estrutura ao redor da questão do minimamente necessário a ser feito para que se garanta que um determinado currículo formativo seja considerado válido para o nível de uma educação superior, fazendo dele, na expressão de Brito (2020), um mercado fast-food.

Ao se colocar restritamente a serviço da sociedade de consumo, a Universidade Econômica está obviamente sujeita às leis do mercado, à sua lógica utilitária. Sua função é atender às demandas do mercado, treinar para a produção, oferecer serviços, administrá-los e comercializá-los. O fato de a universidade atender a essas demandas, isso não nos parece grave, porque, entre outras coisas, é condição sine qua non de sua existência, em larga escala, o vínculo com a vida social, associado aos vínculos-chave como teoria e prática, ciência e técnica, cultura e vida, e tantos outros pares que por isso se correlacionam. O problema é que a Universidade Econômica, sob o desejo voraz da economia de mercado, passa a pensar e a operar apenas sobre aquilo que o mercado impõe - e isso engloba ensino, pesquisa e extensão. Na Universidade Econômica, o conhecimento encontra-se 
cada vez mais subordinado ao que dita a economia produtiva, ao determinismo econômico que rege nossos modelos sociais. De resto, a universidade econômica, sujeita aos impulsos utilitários e pragmáticos da sociedade do consumo, é obrigada a fomentar a competitividade, deixando os sujeitos suscetíveis ao mercado. Seu campo de força é o para quê, e não o quê ou o porquê.

\section{CONSIDERAÇÕES FINAIS}

O caminho empreendido até aqui permitiu ver que a instituição universitária ocidental durante o seu período de formação e consolidação cultivou e avançou a partir de uma intencionalidade, i.e., de uma racionalidade subjacente que a estruturou e sedimentou. O modelo inicial do espaço para o saber universal, à medida do seu avanço, foi cedendo lugar a modelos mais polarizados, focados em algumas particularidades, tais como o visto no estilo de Humboldt e da instituição Napoleônica. Da mesma forma, a intitulada Universidade Econômica, que em muitos casos tem sido tomada e associada a um bem de consumo, tem desempenhado um papel de produtora de meios e expertises para o desenvolvimento de uma sociedade baseada na perspectiva da produção e da renovação contínua dos serviços e produtos estigmatizados sob a lógica do mercado produtivo e do mercado consumidor.

O papel tradicional das universidades na formação e na qualificação de indivíduos, com o consequente acréscimo do ethos por excelência da investigação científica, ou seja, da produção de conhecimentos socialmente relevantes, está, gradualmente, tornando-se obsoleto, apesar de ser, como sabemos, o paradigma que mantém a estrutura universidade. O sucesso econômico nas últimas décadas de algumas regiões do mundo (América do Norte, por exemplo), com um papel interessante na interação universidade-empresa, tem feito com que as políticas públicas atribuam cada vez mais importância ao papel da universidade no enfrentamento dos problemas sociais e, em geral, na produção de inovação e, mais ainda, na oferta de mão de obra suficiente para manutenção da economia. A função social da universidade atualmente, do prestígio institucional ao posicionamento ético, alterando, como vimos, os seus modelos, relaciona-se não apenas à mudança na forma de produção do conhecimento, hoje mais transdisciplinar e aplicado, mas também à verificação progressiva de que tudo que ali é produzido na busca de soluções úteis e imediatas e na adoção da inovação tecnológica como jargão de sua autenticidade. 
O que se nota com isso é que algumas dimensões presentes na proposta original da universidade, tais como o princípio de universalidade do saber, da erudição e da formação humanística, principalmente no modelo de Humboldt e no Napoleônico, vem sendo substituído por uma formação de caráter eminentemente técnico que visa à produção de mão de obra especializada no menor tempo possível. De certa monta, é possível notar que a lógica do Mínimo Produto Viável, MVP, no acrônimo inglês, parece ter avançado sobre os lugares universitários, criando, com isso, espaços de falas mercantilmente comprometidos. Os espaços de ensino-aprendizagem não têm apenas replicado o modelo das linhas de produção, mas tem adotado, cultivado e promovido uma visão de mundo mercantil. Afirmar que os modelos precedentes foram melhores, além de soar anacrônico, poderia parecer saudosista, o que de ambas as formas seria equivocado. O presente estudo buscou construir uma pesquisa transversal, cujo objetivo não é judiciar, mas sim esclarecer ao leitor/pesquisador do campo da educação que a instituição universitária, assim como qualquer outra criação do engenho humano, ao longo da sua história, tem servido a uma lógica social que não lhe é inerente, mas sim situacional.

Tomar o modelo da Universitas medieval, o modelo Humboldtiano ou o Napoleônico e transportá-lo para os nossos dias sem as devidas adaptações e releituras seria, quando muito, ingênuo. A despeito disso, há dois elementos que precisam ser reverdecidos: o primeiro é o espírito crítico dentro das instituições. E disto decorre a necessidade do investimento em estratégias institucionais e políticas afirmativa em prol de uma autenticidade e criticidade do espaço universitário. Sabemos que, por diversos fatores, o tema da autonomia universitária no Brasil é ainda distante e, em muitos sentidos, não pode ser empregado stricto sensu, haja vista as diversas camadas regulatórias e limitadores aos quais as instituições universitárias precisam se submeter ou adequar-se. Diante disso, é importante valorizar a dimensão da autenticidade das instituições no seu processo de indução social e transformação do espaço físico simbólico. Quanto ao segundo ponto, a postura crítica, inerente a todo processo de investigação, deve ser redescoberta como um caminho para, inquirindo-se pelos fundamentos e pelas dinâmicas internas da realidade, chegar-se à formação de um ser humano mais comprometido com o seu meio e a sua história.

A universidade deve ser vista, nos dias de hoje, como um ator capaz de diluir as distâncias entre os vários nós dos sistemas de inovação a que pertence. 
A universidade de hoje tem de ser uma universidade socialmente comprometida, que reconhece a importância da construção de redes com empresas locais e instituições governamentais locais, que se conecta com atores nacionais e internacionais para atualizar conhecimentos e manter um background necessário. Além disso, deve assumir a responsabilidade de responder às expectativas que os diferentes atores nela depositam. Todos esses aspectos são considerados elementos-chave na definição de sua estratégia e desempenho. Desta forma, o ideal emancipatório da universidade Humboldtiana e o imperativo nacionalista da Universidade Napoleônica parecem perder vigor dentro de um contexto que se arroga as prerrogativas globais. Contudo, é forçoso lembrar que, muito embora a universidade econômica esteja se estruturando para atender a lógica de um dito mercado global, os seres humanos, por elas e nelas formados, ainda continuam marcados pela dimensão situacional da sua contingente história. Ao considerar tais realidades, resta-nos concluir, ainda, sempre de modo provisório, que uma via média entre o modelo clássico de universidade, marcado pelo elitismo e pela erudição, e o da universidade econômica, marcada pelo tecnicismo e pela velocidade da formação, poderia ser uma universidade integradora, a qual, não obstante esteja em contínuo e profundo diálogo com as demandas da sociedade e esteja nela inserida como copartícipe, não perca de vista a dimensão da autenticidade e da criticidade que visa não apenas formar instrumentos e mão de obra de caráter econômico, mas sim que consiga criar paisagens educativas capazes de apontar para a integralidade e a significatividade da vida.

\section{REFERÊNCIAS}

ADORNO, T. W.; HORKHEIMER, M. Dialética do esclarecimento. Tradução de Guido Antonio de Almeida. Rio de Janeiro: Jorge Zahar, 1985.

BARRIENTOS, O. P.; ZAROR, C.; HERNÁNDEZ, J. R. La Universidad de Concepción y su aporte al desarrollo de la región del Biobío y el país. Revista NUPEM, Campo Mourão, v. 12, n. 27, p. 180-99, set./dez. 2020.

BAUMAN, Z. Modernidade Líquida. Tradução de Plínio Dentzien. Rio de Janeiro: Jorge Zahar, 2001.

BRITO, J. R. M. O mercado fast-food do ensino jurídico brasileiro: análise econômica do direito e a eficiência das políticas públicas. Londrina: Thoth, 2020. 
CARDOSO, C. A.; FERREIRA, V. A.; BARBOSA, F. C. G. (Des)igualdade de acesso à educação em tempos de pandemia: uma análise do acesso às tecnologias e das alternativas de ensino remoto. Revista Com Censo: Estudos Educacionais do Distrito Federal, [s.I.], v. 7, n. 3, p. 38-46, ago. 2020.

CHAUÍ, M. A universidade pública sob nova perspectiva. Revista Brasileira de Educação, Rio de Janeiro, n. 24, p. 5-15, set./dez. 2003.

CORREIA, F. C. Universidade e inconformismo: a crítica ao pensamento instrumental. 2016. Dissertação (Mestrado em Educação) - Universidade de Sorocaba, Sorocaba, São Paulo, 2016.

CORREIA, J. A. Construção político-cognitiva da exclusão social no campo educativo. In: Bianchetti, L.; Correia, J. A. In/exclusão no trabalho e na educação: aspectos mitológicos, históricos e conceituais. Campinas: Papirus, 2011. p. 217-46.

COSTA, F. N. Comportamento dos investidores: do homo economicus ao homo pragmaticus. Texto para discussão IE/UNICAMP, Campinas, n. 165, ago. 2009. Disponível em: https://www.eco.unicamp.br/images/arquivos/artigos/1795/texto165.pdf. Acesso em: 22 abr. 2021.

CLARKE, R. N. Ensuring the education and skills needed for ICT employment and economic growth. In: PUPILLO, L.; NOAM, E.; WAVERMAN, L. (Ed.). Digitized Labor, [s.I.], Palgrave Macmillan, p. 201-14, 2018. Doi: https://doi.org/10.1007/978-3-319-78420-5_12

DIAS SOBRINHO, J. Universidade fraturada: reflexões sobre conhecimento e responsabilidade social. Avaliação, Sorocaba; Campinas, São Paulo, v. 20, n. 3, p. 581-601, nov. 2015

DIAS SOBRINHO, J. Educação Superior: Bem público, equidade e democratização. Avaliação, Sorocaba; Campinas, São Paulo, v. 18, n. 1, p. 107-26, mar. 2013.

DIAS SOBRINHO, J. Dilemas da Educação Superior no mundo globalizado: sociedade do conhecimento ou economia do conhecimento? São Paulo: Casa do Psicólogo, 2005.

DIAS SOBRINHO, J. Avaliação ética e política em função: da educação como direito público ou como mercadoria? Educação e Sociedade, Campinas, v. 25, n. 88, p. 703-25, out. 2004.

DIAS SOBRINHO, J. Universidade e avaliação: entre ética e o mercado. Florianópolis: Insular, 2002.

FERNANDES, F. As mudanças sociais no Brasil. In: IANNI, O. (Org.). Florestan Fernandes: sociologia crítica e militante. São Paulo: Expressão Popular, 2004. 
FERNANDES, F. Universidade brasileira: reforma ou revolução? São Paulo: Alfa-Ômega, 1975.

FREITAG, M. Le naufrage de l'université et autres essays d'épistémologie politique. Paris: Editions de la écouverte, 1995.

GOERGEN, P. Educação como direito de cidadania e responsabilidade do Estado. Educação e Sociedade, Campinas, v. 34, n. 124, p. 723-42, jul./set. 2013.

GOERGEN, P. Educação para a responsabilidade social: pontos de partida para uma nova ética. In: SEVERINO, F. E. S. Ética e formação de professores: política, responsabilidade e autoridade em questão. São Paulo: Cortez, 2011. p. 93-129.

GOERGEN, P. Educação instrumental e formação cidadã: observações críticas sobre a pertinência social da universidade. Educar, Curitiba, n. 37, p. 59-76, maio/ago. 2010.

HABERMAS, J. O discurso filosófico da modernidade. São Paulo: Martins Fontes, 2000.

HABERMAS, J. Pensamento pós-metafísico. Rio de Janeiro: Tempo Brasileiro, 1990.

HABERMAS, J. Consciência moral e agir comunicativo. Rio de Janeiro: Tempo Brasileiro, 1989.

HUMBOLDT, W. V. Schriften zur Politik und zum Bildungswesen. Werke IV, 2010.

HUMBOLDT, W. V. Sobre a organização interna e externa das instituições científicas superiores em Berlim. In: CASPER, G.; HUMBOLDT, W. V. Um mundo sem universidades? 2. ed. Rio de Janeiro: EdUERJ, 2003. p. 15-34.

MARTINS, A. S. Burguesia e a nova sociabilidade: estratégias para educar o consenso no Brasil contemporâneo. 2007. Tese (Doutorado em Educação) - Universidade Federal Fluminense, Niterói, RJ, 2007.

MONTEIRO, J. C. S. Os processos formativos na sociedade da Informação. Revista Ensaios e Pesquisa em Educação e Cultura, Rio de Janeiro, v. 5, n. 8, p. 140-53, 2020. Doi: https:// doi.org/10.29327/211303.5.8

NEVES, L. M. W. A sociedade civil como espaço estratégico de difusão da nova pedagogia da hegemonia. In: NEVES, L. M. W. (Org.). A nova pedagogia da hegemonia: estratégias do capital para educar o consenso. São Paulo: Xamã, 2005, p. 85-125.

NEVES, L. M. W. (Org.). O empresariamento da educação. São Paulo: Xamã, 2002.

OLIVEIRA, Romualdo Portela de. A Transformação da Educação em Mercadoria no Brasil, 
Educação \& Sociedade, Campinas, v. 30, n. 108, p. 739-60, out. 2009

ROSA, H. Aceleração: a transformação das estruturas temporais na modenidade. São Paulo: UNESP. 2019.

RODRIGUES, J. Os empresários e a educação superior. Campinas: Autores Associados, 2007.

RODRIGUES, J. O moderno príncipe industrial: o pensamento pedagógico empresarial da Confederação Nacional da Indústria. Campinas: Autores Associados, 1998.

TEIXEIRA, A. Uma perspectiva da educação superior no Brasil. Revista Brasileira de Estudos Pedagógicos, Rio de Janeiro, v. 50, n. 11, p. 21-82, jul./set. 1968.

TEIXEIRA, A. A universidade de ontem e de hoje. Revista Brasileira de Estudos Pedagógicos, Rio de Janeiro: INEP; CBPE, v. 42, n. 95, p. 27-47, jul./set. 1964.

SGUISSARDI, V. Educação superior no Brasil. Democratização ou massificação mercantil? In: Educação \&. Sociedade, Campinas, v. 36, n. 133, p. 867-89, out./dez., 2015.

SILVA, C. R. S.; NUNES, J. V.; TEIXEIRA, T. M. C. Do conceito de informação ao discurso sobre competência em informação. InCID: Revista de Ciência da Informação e Documentação, [s.l.], v. 11, n. 2, p. 185-205, 2020. Doi: 10.11606/issn.2178-2075.v11i2p185-205.

\section{Sobre os autores:}

Fabio Caires Correia: Doutor em Filosofia pela Pontifícia Universidade Católica do Rio Grande do Sul (PUC-RS). Pesquisador associado à Cátedra UNESCO de Juventude, Educação e Sociedade. E-mail: fabio.correia@catolica-to.edu.br, Orcid: https://orcid.org/0000-0002-1768-3720

Gillianno José Mazzetto de Castro: Pós-doutorando em Filosofia pela Pontifícia Universidade Católica do Rio Grande do Sul (PUC-RS). Doutor e mestre em Psicologia pela Universidade Católica Dom Bosco (UCDB), com estágio doutoral na Universidade da Califórnia, Berkeley (EUA). Pós-graduação em Growth Hacking \& Agile Mindset pela HSM University. Graduado em Filosofia pela UCDB. Pesquisador da Cátedra UNESCO da Juventude. E-mail: gillianno@gmail.com, Orcid: https://orcid.org/0000-0003-3354-4330

\section{Recebido em: 30/04/2021 Aprovado em: 24/09/2021}


